Kevin N. Sheth, MD John R. Sims, MD

Correspondence \& reprint requests to Dr. Sheth: kshethmd@gmail.com

\title{
Neurocritical care and periprocedural blood pressure management in acute stroke
}

\section{ABSTRACT}

The purpose of this article is to review the literature on periprocedural blood pressure (BP) management in acute ischemic stroke and to establish guidelines regarding management of BP. These guidelines are drawn from available evidence and expert opinion. This article reviews the pathophysiologic considerations of BP in ischemic stroke. It also examines the natural history of BP changes during stroke, as well as data on induced BP reduction and hypertension, particularly in light of reperfusion therapy. Finally, the article reviews major ongoing clinical trials for BP management in this setting. Recommendations made in this article may serve as a benchmark for future research in BP management in this patient population. Neurology ${ }^{\circledR} 2012 ; 79$ (Suppl 1):S199-S204

\section{GLOSSARY}

$\mathbf{B P}=$ blood pressure; $\mathbf{C B F}=$ cerebral blood flow; $\mathbf{C P P}=$ cerebral perfusion pressure; $\mathbf{D B P}=$ diastolic blood pressure; $\mathbf{M A P}=$ mean arterial pressure; NIHSS = NIH Stroke Scale; NINDS = National Institute of Neurological Disorders and Stroke; SBP = systolic blood pressure; tPA = tissue plasminogen activator.

INTRODUCTION AND PATHOPHYSIOLOGY Blood pressure (BP) is largely a surrogate for cerebral perfusion pressure (CPP). During acute ischemic stroke, cerebral blood flow (CBF) is predominantly influenced by mean arterial pressure (MAP), ${ }^{1}$ as intracranial pressure changes are negligible. A number of other physiologic factors also influence CBF, including oxygen and carbon dioxide partial pressure, ${ }^{2}$ cerebral metabolism, ${ }^{3}$ temperature, ${ }^{4,5}$ and blood viscosity. ${ }^{6,7} \mathrm{CBF}$ is kept relatively constant across a wide range of perfusion pressures by adjustments in the diameter of vessel resistance, in a process known as autoregulation. In healthy subjects, autoregulation is maintained over a range of CPP (50-150 $\mathrm{mm} \mathrm{Hg})$; however, when autoregulation is lost, the relationship between CPP and CBF becomes more linear. As a result of occlusion or severe stenosis, resistance to flow increases, and dilation of arterioles compensates by lowering resistance to flow in the downstream arterial bed. ${ }^{8,9}$ A complex series of events, many of which are mediated in part by nitric oxide, ensures $\mathrm{CBF}$ compensation for changes in MAP. One of the many effects of ischemia on brain tissue is the loss of autoregulation. In this setting, $\mathrm{CBF}$ changes directly with alteration in MAP, rendering ischemic brain vulnerable to minimal variation of the systemic BP. Furthermore, arteriolar tone and consequent changes in $\mathrm{CBF}$ are the result of change in the local physiologic milieu, manifested by changes in factors such as extracellular potassium concentration and sustained depolarization. The loss of autoregulation during cerebral ischemia has been extensively demonstrated both in humans ${ }^{1}$ and in nonhuman primates. ${ }^{10}$

PET and autoradiography shed light on the series of events that follow cerebral ischemia. In particular, in several species, including humans, several other compensatory mechanisms occur upon reduction of CBF, such as increase in cerebral blood volume, increase in oxygen extraction fraction, and decrease in oxygen consumption. A detailed description of these important phenomena is beyond the scope of this review. In brief, as CBF decreases within the cerebral tissue affected by ischemia, there are regional variations in the execution of these compensatory mechanisms, depending on degree of ischemia, duration of ischemia, degree of collateral circulation, and phylogenetic susceptibility to ischemia of a particular neuronal subpopulation. As a result of these events, the ischemic tissue is divided into a core and a penumbra. ${ }^{11}$ The core is considered to be tissue already severely damaged by ischemia and most likely destined to infarction. The penumbra is the ischemic area surrounding the core that has the potential for recovery upon restoration of normal CBF

From the Department of Neurology (K.N.S.), University of Maryland School of Medicine, Program in Shock, Trauma, and Anesthesiology Research (STAR), R. Adams Cowley Shock Trauma Center, Baltimore; and Department of Neurology (J.R.S.), Massachusetts General Hospital, Boston, MA.

Study funding: This work was supported by an American Academy of Neurology Clinical Research Award to Dr. Sheth and by an NIH grant, K08 NS049241, to Dr. Sims. Dr. Sims has received research support from the NIH.

Go to Neurology.org for full disclosures. Disclosures deemed relevant by the authors, if any, are provided at the end of this article. 
values. ${ }^{12}$ On the basis of these data, adequate levels of MAP play a critical role in the survival of the penumbral tissue. ${ }^{10,12,13}$

Although the evidence is ample to suggest benefit of MAP maintenance or its elevation during ischemia, it cannot be viewed independently of CBF. BP is a surrogate for $\mathrm{CBF}$ and represents a transmural pressure that is distributed throughout the vascular tree. Transmural pressure represents a potential negative influence on transmural rupture (cerebral hemorrhage) and net bulk flow across capillary beds, thereby worsening cerebral edema (Starling's equation) and secondary organ injury to heart and lung. Currently it is unclear how to appropriately weigh the benefits and risks to measure optimal outcome. The benefits and risks are not constant but instead are interdependent on vessel diameter, transmural pressure, and possible transmural rupture.

\section{Recommendation}

1. Prospective studies are needed to evaluate CBF via imaging and physiologic continuous monitoring after BP manipulation during acute ischemia.

NATURAL HISTORY OF BLOOD PRESSURE IN ACUTE ISCHEMIC STROKE In patients with ischemic stroke, as many as $60 \%$ of patients have a systolic blood pressure (SBP) greater than $160 \mathrm{~mm} \mathrm{Hg}$. This elevation can persist for hours to days. ${ }^{14} \mathrm{Al}$ though some portion of elevated BP might be due to a compensatory need to increase $\mathrm{CBF}$, other factors such as stress, pain, discomfort, and intrinsic hypertension likely play a role as well. ${ }^{15,16}$ Despite the etiology, BP has a tendency to normalize over 24 to 48 hours. ${ }^{16,17}$ With regard to stroke subtype, evidence suggests that lacunar stroke may be associated with higher initial SBP ${ }^{16}$ than nonlacunar stroke. Consequently, lacunar stroke-associated BP may decrease over 24 hours to a greater degree than nonlacunar stroke. ${ }^{18}$ Most data regarding the association of initial BP on stroke outcome indicate a U-shaped curve. ${ }^{16,19}$ Patients with lower BP have worse outcome than those with higher BP. Still, those patients with SBP greater than $180 \mathrm{~mm} \mathrm{Hg}$ seem to have worse outcome than those with BP in the 150 to 180 range. From the International Stroke Trial Registry, there was either a $3.8 \%$ or $17.9 \%$ increase in early mortality for every $10-\mathrm{mm} \mathrm{Hg}$ change above or below $150 \mathrm{~mm} \mathrm{Hg}$, respectively. ${ }^{16}$ Others have suggested that initial high BP predicts poor outcome only in combination with impaired consciousness. ${ }^{1720}$ However, other data suggest that initial $\mathrm{BP}$ is not associated with mortality, but elevated BP over the ensuing 48 hours is associated with higher NIH Stroke Scale (NIHSS) score and greater mortality. ${ }^{21}$
Whether or not high BP is a marker of disease severity or a modifiable mediator with a direct mechanistic relationship to outcome is unclear. We propose that the likely explanation is a component of both. At one extreme, increased BP is a secondary response to cerebral ischemia. As the size and degree of ischemia increase, with individual variability, the BP may increase to support perfusion. However, this response is pathologic, and, like cardiac ventricular remodeling in response to chronic hypertension, this compensatory effort by the body can have pathologic consequences (heart failure or brain failure). The period and setting of brain ischemia are often confounded by other variables that may increase BP independently: anxiety, pain, fever, inflammation, tissue plasminogen activator ( $\mathrm{tPA}$--mediated hemorrhage. Ultimately, clarity with regard to the role of $\mathrm{BP}$ rise in the setting of acute ischemia can be answered only with prospective, randomized interventions. Such trials would need to have consistent management strategies for enrolled patients.

It should be noted that it is not clear whether systolic, diastolic, or mean arterial BP is superior for determining outcomes. Although this is unproven, higher spontaneous initial BP might maintain CBF for penumbral tissue. This elevation in BP places patients at an increased risk of hemorrhage, edema, and secondary organ injury. Increased systemic BP increases systemic vascular resistance, thereby increasing myocardial strain and oxygen demand. Increased resistance and myocardial strain can also lead to pulmonary edema, especially in the setting of any volume overload. The correlation of high BP and increased risk of intracerebral hemorrhage is unknown. There was no association with BP and hemorrhage in the European Cooperative Acute Stroke Study (ECASS) I, International Stroke Trial, ${ }^{16} \mathrm{Na}-$ tional Institute of Neurological Disorders and Stroke (NINDS), ${ }^{23}$ or Interventional Management of Stroke ${ }^{24}$ trials. However, elevated BP is associated with intracerebral hemorrhage after administration of tPA, ${ }^{25-27}$ streptokinase, ${ }^{28}$ or urokinase. ${ }^{29}$ Existing data support an increased risk of cerebral edema when there is simultaneous high BP. ${ }^{16,18,30}$ The excessive risk of patients presenting with lower BP is likely secondary to failure to maintain sufficient CBF for penumbral survival. Failure to maintain sufficient $\mathrm{CBF}$ is also coupled with higher occurrence of larger stroke, cardioembolic stroke, and heart failure. ${ }^{16,30}$

\section{Recommendation}

1. Prospective studies are needed to determine the association of BP and the risk of hemorrhage, cerebral edema, and secondary organ injury, which are based on stroke severity, neurologic deterioration, infarct volume, and other factors associated with poor outcome. 
BLOOD PRESSURE MANAGEMENT IN THE SETTING OF THROMBOLYTIC AND REVASCULARIZATION THERAPY In the NINDS recombinant tPA trial, there was a similar incidence of hypertension in the placebo recipients and tPAtreated patients. Hypertensive patients treated with tPA who also received antihypertensive medications had a less favorable outcome at 3 months. ${ }^{31}$ In contrast, treatment with recombinant tPA in the NINDS trial was associated with greater BP reduction than placebo. ${ }^{32}$ Also, in patients treated with recombinant tPA, higher SBP was associated with persistent occlusion, as assessed by ultrasound, but without worse clinical outcomes at 3 months. ${ }^{33}$ Cause and effect cannot be inferred but supported the hypothesis that elevated BP is required to maintain penumbral flow. This evidence is supported by spontaneous reductions in BP after recanalization ${ }^{34}$ and increases in infarct volume in the setting of large BP fluctuations without recanalization. ${ }^{35}$ Furthermore, hemorrhagic transformation after thrombolytic therapy, consistent with recanalization and the potential for increased brain edema, was associated with a trend toward lower SBP. ${ }^{36}$ Conversely, in the setting of thrombolytic therapy, there is significant evidence supporting an association with elevated BP and intracerebral hemorrhage. ${ }^{26-30}$

\section{Recommendations}

1. In agreement with the 2007 American Stroke Association Guidelines, ${ }^{37}$ SBP should be kept under $180 \mathrm{~mm} \mathrm{Hg}$ and diastolic BP (DBP) under 105 $\mathrm{mm} \mathrm{Hg}$ in patients who have received thrombolytic or interventional therapy for the immediate postprocedure period. There are no data to suggest a particular antihypertensive medication to use when it is necessary to lower BP. However, medications that can be rapidly titrated are preferred.

2. Prospective CBF studies are needed to assess any relationship between arterial recanalization and BP that could account for differences in collateral circulation.

3. Prospective randomized trials for BP treatment after recanalization therapy, either drug thrombolysis or mechanical thrombectomy, are needed and should be stratified according to absence or presence of recanalization.

4. Prospective studies are needed to assess the natural history of BP in the setting of interventional therapies. These studies should examine the association of infarct volume, volume of at-risk tissue, collateral flow, recanalization flow, and location of vessel occlusion.
LOWERING BP IN ACUTE ISCHEMIC STROKE

Because of the direct relationship between CPP and MAP, lowering BP can diminish $\mathrm{CBF}$ to ischemic brain tissue. In a multivariate analysis, accounting for NIHSS score and stroke location, ${ }^{38} \mathrm{BP}$ reduction in the first 24 hours was independently associated with poor outcome. A Cochrane database review of trials aimed at acute or subacute reduction of BP after ischemic stroke included 5 randomized trials and 218 patients. There was insufficient evidence to support lowering BP in patients with acute stroke. ${ }^{39}$ In fact, 3 randomized trials testing nimodipine or $\beta$-blockers, BEST, ${ }^{40}$ INWEST, ${ }^{41}$ and VENUS, ${ }^{42}$ all had worse outcomes in the active treatment group. Only interventions in BEST and INWEST were associated with BP lowering. More recently, a trial of candesar$\tan$ administration within the first 36 hours of stroke (mean time from stroke onset to treatment $=30$ hours) compared to 7 days of placebo found no significant difference in BP decline and a significant improvement in mortality and recurrent stroke at 1 year. ${ }^{43}$ The lack of effect on BP reduction suggests a mechanism other than BP regulation for this protective effect. In another trial, 40 hypertensive (SBP $>140 \mathrm{~mm} \mathrm{Hg}$ or DBP $>90 \mathrm{~mm} \mathrm{Hg}$ ) ischemic stroke patients were randomized to oral lisinopril or placebo within 24 hours of stroke onset. These investigators found significant differences in BP reduction without any difference in clinical outcome. This trial was not powered for clinical outcome. ${ }^{44}$ It remains to be proven whether certain classes of antihypertensives might have beneficial effects on stroke outcomes regardless of $\mathrm{BP}$ changes.

\section{Recommendations}

1. In agreement with the 2007 American Stroke Association Guidelines, ${ }^{37}$ for patients not receiving thrombolytic or interventional therapy, BP medication should be withheld for the first 24 hours unless SBP is above $220 \mathrm{~mm} \mathrm{Hg}$ or DBP is above $110 \mathrm{~mm} \mathrm{Hg}$.

2. After 24 hours, BP medications may be restarted safely in a general stroke population, although there are limited high-level data to support this recommendation.

3. Prospective outcome studies are needed to evaluate early initiation of BP therapy in the setting of documented presence or absence of recanalization.

4. Studies are needed to determine whether hypertensive patients with persistent penumbra at 24 hours benefit from the withholding or institution of antihypertensive therapy.

INDUCED HYPERTENSION Because of the desire to improve $\mathrm{CBF}$ to penumbral tissue, either through a flow-limiting lesion or through collateral circula- 
tion, several groups have attempted to induce hypertension in patients with acute ischemic stroke. For this purpose, $\alpha$-adrenergic agonists are an attractive choice, as selective vasoconstriction of the peripheral arterial bed can be achieved without involvement of cerebral arteries. ${ }^{45}$ In another report, ${ }^{46}$ hypertension was prospectively induced in 13 patients within 12 hours of presentation. None of the patients had serious adverse events, and $54 \%$ had an improvement of at least 2 points on the NIHSS, attributable to the $\mathrm{BP}$ increase. In a retrospective report, ${ }^{47} 34$ ischemic stroke patients with SBP $<140 \mathrm{~mm} \mathrm{Hg}$ were treated with hypertensive therapy (average time of stroke onset to treatment $=13$ hours). Early improvement, defined as a 2-point decrease in NIHSS within 8 hours of therapy, was seen in $19 \%$ of patients. Treatment was associated with 1 cardiac arrhythmia and 1 fatal intracerebral hemorrhage. Other studies of induced hypertension in the subacute phase, i.e., initiation within 7 days of stroke onset, in patients selected for diffusion-perfusion mismatch have had mixed results. ${ }^{48,49}$ The only trial that was randomized demonstrated a significant improvement in NIHSS score for induced hypertension. ${ }^{48}$ It is unclear whether these subacute trials of induced hypertension apply in the acute periprocedural time frame for endovascular treatment. Although there appears to be promise for induced hypertension in the acute phase, it is unclear how best to select patients who might benefit and whether a benefit of improved neurologic function will outweigh the potential complications of intracerebral hemorrhage, cerebral or pulmonary edema, and myocardial infarction. Unfortunately, a prior study, Induced Hypertension for Acute Ischemic Stroke, was terminated, in part because of poor enrollment.

\section{Recommendations}

1. Arterial hypotension (SBP $<120 \mathrm{~mm} \mathrm{Hg}$ ) should be evaluated and corrected, given the strong association with higher mortality.

2. Prospective, randomized trials evaluating induced hypertension are needed. Such trials should also evaluate patient selection on the basis of presenting BP, presence of mismatch, CBF studies, timing of induced hypertension, and agents used. Such trials should include location of vessel involvement, degree of collateral circulation, extent of occlusion, and tissue at risk.

RANDOMIZED TRIALS Only the Controlling Hypertension and Hypotension Immediately Post Stroke (CHHIPS) trial ${ }^{50}$ enrolled patients no later than 12 hours from onset into a randomized BP arm. This arm will evaluate induced hypertension in patients presenting with SBP $\leq 140 \mathrm{~mm} \mathrm{Hg}$. Although the remaining trials are important, they are unlikely to address the question of how to manage the vast majority of hyperacute patients, those typically within the 8-hour time window, who are undergoing an interventional procedure for recanalization. Although not strictly a BP trial, the Safety and Efficacy of NeuroFlo Technology in Ischemic Stroke (SENTIS) trial $^{51}$ is currently randomizing patients within 14 hours to partial occlusion of aortic outflow or best management. Data from deployment of this intra-aortic device, which spans above and below the renal arteries, suggests that the procedure can elevate $\mathrm{CBF}$ without change in systemic BP. ${ }^{52}$

SUMMARY Many patients with acute stroke present with hypertension. There are few data to guide the management of BP within the first 24 hours. Substantial circumstantial evidence suggests that elevated BP might provide needed CBF to penumbral tissue; however, this benefit is associated with higher rates of intracerebral hemorrhage and edema, as well as secondary organ injury to the heart, lungs, and kidneys. Those patients who present with hypotension or relative hypotension (SBP $<120-140 \mathrm{~mm} \mathrm{Hg}$ ) are at greatest risk for neurologic deterioration. This group likely has a complex interaction of large strokes and substantial cardiovascular disease. In the absence of data, we agree with the current recommendations of the American Stroke Association for acute management of $\mathrm{BP}^{37}$ and therefore have highlighted these recommendations and suggested research efforts.

\section{AUTHOR CONTRIBUTIONS}

Dr. Sheth: drafting/revising the manuscript, study concept or design. Dr. Sims: drafting/revising the manuscript, study concept or design, analysis or interpretation of data, study supervision.

\section{DISCLOSURE}

Dr. Sheth receives research support from the American Academy of Neurology, American Heart Association, Remedy Pharmaceuticals, Brainscope, Inc., and the US Army; served as a paid consultant to Verimed; received compensation for a lecture to the Research Foundation and Kansas City Stroke Symposium; receives royalties from publishing Blueprints Clinical Cases in Neurology; and serves on the editorial board or as section editor for Neurology Today, Frontiers in Hospitalist Neurology, and the Neuro-Critical Care Section for Current Treatment Options in Neurology. Go to Neurology.org for full disclosures.

Received July 9, 2011. Accepted in final form August 26, 2011.

\section{REFERENCES}

1. Zazulia AR, Videen TO, Powers WJ. Symptomatic autoregulatory failure in acute ischemic stroke. Neurology 2007;68:389-390.

2. Koehler RC, Traystman RJ. Bicarbonate ion modulation of cerebral blood flow during hypoxia and hypercapnia. Am J Physiol 1982;243:H33-H40.

3. Ito H, Kanno I, Fukuda H. Human cerebral circulation: positron emission tomography studies. Ann Nucl Med 2005; 19:65-74. 
4. Ehrlich MP, McCullough JN, Zhang N, et al. Effect of hypothermia on cerebral blood flow and metabolism in the pig. Ann Thoracic Surg 2002;73:191-197.

5. Henriksen L. Brain luxury perfusion during cardiopulmonary bypass in humans: a study of the cerebral blood flow response to changes in $\mathrm{CO} 2, \mathrm{O} 2$, and blood pressure. J Cereb Blood Flow Metab 1986;6:366-378.

6. Humphrey PR, Du Boulay GH, Marshall J, et al. Cerebral blood-flow and viscosity in relative polycythaemia. Lancet 1979;2:873-877.

7. Grotta J, Ackerman R, Correia J, Fallick G, Chang J. Whole blood viscosity parameters and cerebral blood flow. Stroke 1982;13:296-301.

8. Aaslid R, Lindegaard KF, Sorteberg W, Nornes H. Cerebral autoregulation dynamics in humans. Stroke 1989;20: 45-52.

9. Reed G, Devous M. Cerebral blood flow autoregulation and hypertension. Am J Med Sci 1985;289:37-44.

10. Jones TH, Morawetz RB, Crowell RM, et al. Thresholds of focal cerebral ischemia in awake monkeys. J Neurosurg 1981;54:773-782.

11. Fisher M, Garcia JH. Evolving stroke and the ischemic penumbra. Neurology 1996;47:884-888.

12. Astrup J, Siesjo BK, Symon L. Thresholds in cerebral ischemia: the ischemic penumbra. Stroke 1981;12:723725.

13. Shin HK, Nishimura M, Jones PB, et al. Mild induced hypertension improves blood flow and oxygen metabolism in transient focal cerebral ischemia. Stroke 2008;39:1548 1555.

14. Wallace JD, Levy LL. Blood pressure after stroke. JAMA 1981;246:2177-2180.

15. Phillips SJ. Pathophysiology and management of hypertension in acute ischemic stroke. Hypertension 1994;23: 131-136.

16. Leonardi-Bee J, Bath PM, Phillips SJ, Sandercock PA. Blood pressure and clinical outcomes in the International Stroke Trial. Stroke 2002;33:1315-1320.

17. Christensen H, Meden P, Overgaard K, Boysen G. The course of blood pressure in acute stroke is related to the severity of the neurological deficits. Acta Neurol Scand 2002;106:142-147.

18. Vemmos KN, Tsivgoulis G, Spengos $\mathrm{K}$, et al. Blood pressure course in acute ischaemic stroke in relation to stroke subtype. Blood Press Monit 2004;9:107-114.

19. Castillo J, Leira R, Garcia MM, Serena J, Blanco M, Davalos A. Blood pressure decrease during the acute phase of ischemic stroke is associated with brain injury and poor stroke outcome. Stroke 2004;35:520-526.

20. Carlberg B, Asplund K, Hagg E. The prognostic value of admission blood pressure in patients with acute stroke. Stroke 1993;24:1372-1375.

21. Aslanyan S, Fazekas F, Weir CJ, Horner S, Lees KR. Effect of blood pressure during the acute period of ischemic stroke on stroke outcome: a tertiary analysis of the GAIN International Trial. Stroke 2003;34:2420-2425.

22. Larrue V, von Kummer R, del Zoppo G, Bluhmki E. Hemorrhagic transformation in acute ischemic stroke: potential contributing factors in the European Cooperative Acute Stroke Study. Stroke 1997;28:957-960.

23. The NINDS t-PA Stroke Study Group. Intracerebral hemorrhage after intravenous t-PA therapy for ischemic stroke. Stroke 1997;28:2109-2118.
24. IMS Study Investigators. Hemorrhage in the Interventional Management of Stroke study. Stroke 2006;37:847851.

25. Larrue V, von Kummer RR, Muller A, Bluhmki E. Risk factors for severe hemorrhagic transformation in ischemic stroke patients treated with recombinant tissue plasminogen activator: a secondary analysis of the EuropeanAustralasian Acute Stroke Study (ECASS II). Stroke 2001; $32: 438-441$

26. Levy DE, Brott TG, Haley EC Jr, et al. Factors related to intracranial hematoma formation in patients receiving tissue-type plasminogen activator for acute ischemic stroke. Stroke 1994;25:291-297.

27. Yong M, Kaste M. Association of characteristics of blood pressure profiles and stroke outcomes in the ECASS-II trial. Stroke 2008;39:366-372.

28. Gilligan AK, Markus R, Read S, et al. Baseline blood pressure but not early computed tomography changes predicts major hemorrhage after streptokinase in acute ischemic stroke. Stroke 2002;33:2236-2242.

29. Tirschwell DL, Coplin WM, Becker KJ, et al. Intra-arterial urokinase for acute ischemic stroke: factors associated with complications. Neurology 2001;57:1100-1103.

30. Vemmos KN, Tsivgoulis G, Spengos K, et al. U-shaped relationship between mortality and admission blood pressure in patients with acute stroke. J Intern Med 2004;255: 257-265.

31. Brott T, Lu M, Kothari R, et al. Hypertension and its treatment in the NINDS rt-PA Stroke Trial. Stroke 1998; 29:1504-1509.

32. Silver B, Lu M, Morris DC, et al. Blood pressure declines and less favorable outcomes in the NINDS tPA stroke study. J Neurol Sci 2008;271:61-67.

33. Tsivgoulis G, Saqqur M, Sharma VK, Lao AY, Hill MD, Alexandrov AV. Association of pretreatment blood pressure with tissue plasminogen activator-induced arterial recanalization in acute ischemic stroke. Stroke 2007;38: 961-966.

34. Mattle HP, Kappeler L, Arnold M, et al. Blood pressure and vessel recanalization in the first hours after ischemic stroke. Stroke 2005;36:264-268.

35. Delgado-Mederos R, Ribo M, Rovira A, et al. Prognostic significance of blood pressure variability after thrombolysis in acute stroke. Neurology 2008;71:552-558.

36. Selim M, Fink JN, Kumar S, et al. Predictors of hemorrhagic transformation after intravenous recombinant tissue plasminogen activator: prognostic value of the initial apparent diffusion coefficient and diffusion-weighted lesion volume. Stroke 2002;33:2047-2052.

37. Adams HP Jr, del Zoppo G, Alberts MJ, et al. Guidelines for the early management of adults with ischemic stroke: a guideline from the American Heart Association/American Stroke Association Stroke Council, Clinical Cardiology Council, Cardiovascular Radiology and Intervention Council, and the Atherosclerotic Peripheral Vascular Disease and Quality of Care Outcomes in Research Interdisciplinary Working Groups. Stroke 2007;38:1655-1711.

38. Oliveira-Filho J, Silva SC, Trabuco CC, Pedreira BB, Sousa EU, Bacellar A. Detrimental effect of blood pressure reduction in the first 24 hours of acute stroke onset. Neurology 2003;61:1047-1051.

39. (BASC) BpiASC. Interventions for deliberately altering blood pressure in acute stroke. Cochrane Database of Systematic Reviews 2001;3. 
40. Barer DH, Cruickshank JM, Ebrahim SB, Mitchell JR. Low dose beta blockade in acute stroke ("BEST" trial): an evaluation. BMJ Clin Res Ed 1988;296:737-741.

41. Ahmed N, Nasman P, Wahlgren NG. Effect of intravenous nimodipine on blood pressure and outcome after acute stroke. Stroke 2000;31:1250-1255.

42. Horn J, de Haan RJ, Vermeulen M, Limburg M. Very Early Nimodipine Use in Stroke (VENUS): a randomized, doubleblind, placebo-controlled trial. Stroke 2001;32:461-465.

43. Schrader J, Luders S, Kulschewski A, et al. The ACCESS Study: evaluation of Acute Candesartan Cilexetil Therapy in Stroke Survivors. Stroke 2003;34:1699-1703.

44. Eveson DJ, Robinson TG, Potter JF. Lisinopril for the treatment of hypertension within the first 24 hours of acute ischemic stroke and follow-up. Am J Hypertens 2007;20:270-277.

45. Bevan JA, Duckworth J, Laher I, Oriowo MA, McPherson GA, Bevan RD. Sympathetic control of cerebral arteries: specialization in receptor type, reserve, affinity, and distribution. Faseb J 1987;1:193-198.

46. Rordorf G, Koroshetz WJ, Ezzeddine MA, Segal AZ, Buonanno FS. A pilot study of drug-induced hypertension for treatment of acute stroke. Neurology 2001;56: $1210-1213$
47. Marzan AS, Hungerbuhler HJ, Studer A, Baumgartner RW, Georgiadis D. Feasibility and safety of norepinephrineinduced arterial hypertension in acute ischemic stroke. Neurology 2004;62:1193-1195.

48. Hillis AE, Ulatowski JA, Barker PB, et al. A pilot randomized trial of induced blood pressure elevation: effects on function and focal perfusion in acute and subacute stroke. Cerebrovasc Dis (Basel) 2003;16:236-246.

49. Koenig MA, Geocadin RG, de Grouchy M, et al. Safety of induced hypertension therapy in patients with acute ischemic stroke. Neurocrit Care 2006;4:3-7.

50. Potter J, Robinson T, Ford G, et al. CHHIPS (Controlling Hypertension and Hypotension Immediately Post-Stroke) Pilot Trial: rationale and design. J Hypertens 2005;23: 649-655.

51. Safety and Efficacy of Neuroflo Technology in Ischemic Stroke (SENTIS). 2008. Available at: http://www.stroke center.org/trials/trialDetail.aspx?tid $=618 \&$ search_string $=$ Neuroflo.) Accessed September 24, 2008.

52. Lylyk P, Vila JF, Miranda C, Ferrario A, Romero R, Cohen JE. Partial aortic obstruction improves cerebral perfusion and clinical symptoms in patients with symptomatic vasospasm. Neurol Res 2005;27(suppl 1):S129S135. 


\section{Neurology}

\section{Neurocritical care and periprocedural blood pressure management in acute stroke}

Kevin N. Sheth and John R. Sims

Neurology 2012;79;S199-S204

DOI 10.1212/WNL.0b013e31826958f4

This information is current as of September 24, 2012

\section{Updated Information \&} Services

References

Subspecialty Collections

Permissions \& Licensing

Reprints including high resolution figures, can be found at: http://n.neurology.org/content/79/13_Supplement_1/S199.full

This article cites 50 articles, 32 of which you can access for free at: http://n.neurology.org/content/79/13_Supplement_1/S199.full\#ref-list1

This article, along with others on similar topics, appears in the following collection(s):

All Cerebrovascular disease/Stroke

http://n.neurology.org/cgi/collection/all_cerebrovascular_disease_strok e Critical care

http://n.neurology.org/cgi/collection/critical_care

Information about reproducing this article in parts (figures,tables) or in its entirety can be found online at:

http://www.neurology.org/about/about_the_journal\#permissions

Information about ordering reprints can be found online:

http://n.neurology.org/subscribers/advertise

Neurology ${ }^{\circledR}$ is the official journal of the American Academy of Neurology. Published continuously since 1951, it is now a weekly with 48 issues per year. Copyright Copyright $@ 2012$ by AAN Enterprises, Inc.. All rights reserved. Print ISSN: 0028-3878. Online ISSN: 1526-632X.

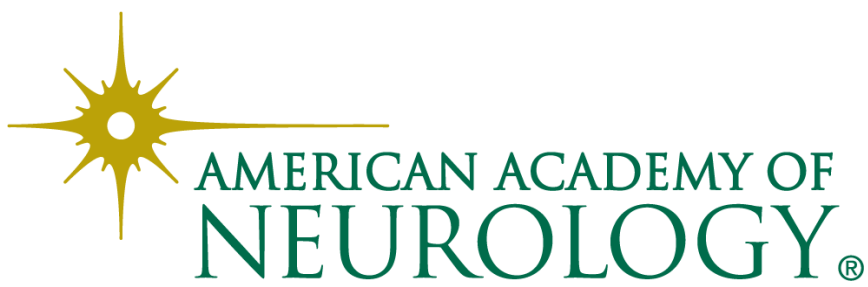

